\title{
Clinical phenotypes of Italian and Spanish patients with $\alpha_{1}$-antitrypsin deficiency
}

\author{
Barbara Piras ${ }^{1,2}$, Ilaria Ferrarotti ${ }^{3,4}$, Beatriz Lara ${ }^{4,5}$, Maria Teresa Martinez $^{6}$, \\ Ana Bustamante ${ }^{7}$, Stefania Ottaviani ${ }^{3}$, Pietro Pirina ${ }^{1,2}$, Maurizio Luisetti ${ }^{3,4}$ and \\ Marc Miravitlles 4,8
}

Affiliations: 'Institute of Respiratory Diseases, Sassari University, Sassari, and ${ }^{3}$ Centre for the Diagnosis of Hereditary Deficiency of $\alpha_{1}$-antitrypsin, Dept of Molecular Medicine, Pneumology Section, University of Pavia, Fondazione IRCCS Policlinico S. Matteo Hospital Foundation, Pavia, Italy. ${ }^{2}$ IDIBAPS Hospital Clinic, Barcelona, ${ }^{5}$ Pneumology Service, University Hospital Arnau de Vilanova, Lleida, ${ }^{6}$ Pneumology Service, Hospital 12 de Octubre, Madrid, ${ }^{7}$ Pneumology Service, Sierrallana Hospital, Torrelavega, and ${ }^{8}$ Pneumology Dept, Hospital Universitari Vall d'Hebron, Clber de Enfermedades Respiratorias (CIBERES), Barcelona, Spain. ${ }^{4}$ Alpha One International Registry (AIR).

Correspondence: M. Miravitlles, Servei de Pneumologia, Hospital Vall d'Hebron, p. Vall d'Hebron 119-129, 08035 Barcelona, Spain. E-mail: marcmasepar.es

ABSTRACT With the aim of providing better clinical characterisation of patients with $\alpha_{1}$-antitrypsin deficiency (AATD), we analysed the data of adult patients with severe AATD enrolled in the Spanish and Italian national registries.

We assessed 745 subjects, 416 of whom were enrolled in the Spanish registry and 329 in the Italian registry. $57.2 \%$ were male and $64.9 \%$ were smokers or former smokers with a mean $\pm \mathrm{SD}$ age of $49.9 \pm 13.8$ years. Most $(81.2 \%)$ were index cases, mainly having the $\mathrm{PI}^{\star} \mathrm{ZZ}$ genotype $(73.4 \%)$, and the mean $\pm \mathrm{SD}$ diagnostic delay was $9.0 \pm 12.1$ years.

Patients with chronic bronchitis were younger, had better preserved lung function and lower tobacco consumption. Overlap patients (chronic obstructive pulmonary disease with asthma) were mainly females, more frequently never-smokers and received respiratory medications more often. $48 \%$ of emphysema, $27.5 \%$ of chronic bronchitis and $44.8 \%$ of overlap subjects were receiving augmentation therapy. Compared with $\mathrm{PI}^{\star} \mathrm{ZZ}$ patients $(\mathrm{n}=547)$, the $\mathrm{PI}^{\star} \mathrm{SZ}(\mathrm{n}=124)$ subjects were older at diagnosis and had more preserved lung function, despite a higher mean smoking consumption.

Early diagnosis of AATD is still an unmet need. Augmentation therapy is administered to similar proportions of patients with different clinical phenotypes. $\mathrm{PI}^{\star} \mathrm{ZZ}$ patients in both registries had more severe respiratory disease than those with $\mathrm{PI}^{\star} \mathrm{SZ}$, despite lower smoking levels.

@ERSpublications

New characterisation of clinical phenotypes in patients with alpha-1 antitrypsin deficiency http://ow.ly/kEHKP

This article has supplementary material available from www.erj.ersjournals.com

Earn CME accreditation by answering questions about this article. You will find these at the back of the printed copy of this issue or online at www.erj.ersjournals.com/misc/cmeinfo.xhtml

Received: July 072012 | Accepted after revision: Oct 192012 | First published online: Dec 062012

Support statement: Barbara Piras has been a recipient of an Erasmus Placement fellowship (number 2011-1-IT2-ERA0225910) in the Hospital Clinic in Barcelona (Spain). The Italian AATD detection programme gratefully acknowledges the continuing support from Talecris/Grifols, Kedrion Italy and the Fondazione IRCCS Policlinico San Matteo. The Spanish registry also acknowledges the continuing support from Talecris/Grifols.

Conflict of interest: Disclosures can be found alongside the online version of this article at www.erj.ersjournals.com

Copyright @ERS 2013 


\section{Introduction}

Hereditary $\alpha_{1}$-antitrypsin deficiency (AATD) is a rare condition associated with an increased risk of pulmonary and hepatic disease. This condition is inherited as an autosomal codominant condition and is characterised by reduced $\alpha_{1}$-antitrypsin $\left(\alpha_{1}\right.$-AT) serum levels [1,2], affecting approximately one in 20005000 individuals $[3,4]$.

There are $>120$ biochemical genetic variants of $\alpha_{1}$-AT, which are classified into three major categories: 1) normal, with genotype $M$, characterised by $\alpha_{1}$-AT within normal ranges; 2 ) deficient, characterised by reduced but detectable $\alpha_{1}$-AT plasma levels with genotypes Z, S and M-like; and 3) null, currently designated Q0, with no detectable plasma levels [5,6]. The main target of $\alpha_{1}$-AT is neutrophil elastase, which is irreversibly bound and inactivated during a process that consumes the $\alpha_{1}$-AT molecules as well [1].

The condition was first recognised in 1963 [7] and, as for other rare diseases, the difficulties in the diagnosis and management of these patients soon promoted the creation of different national registries [8, 9]. After a World Health Organization meeting [10] in 1997, the Alpha One International Registry (AIR) was founded in order to establish an international patient database and to encourage research and promote knowledge of the disease [11]. Despite the improvements achieved since then, the diagnosis of AATD is often delayed [12] and this time lag may affect the prognosis of affected individuals.

With the aim of better describing the clinical manifestations of patients with AATD, we compared the characteristics of patients from two large national registries and evaluated the differential aspects of individuals with different $\alpha_{1}$-AT genotypes and clinical phenotypes.

\section{Methods}

This was an observational study in patients with severe AATD enrolled in the Spanish (Registro Español de Pacientes con Déficit de $\alpha_{1}$-antitripsina (REDAAT)) and Italian (Registro Italiano per la Carenza Severa di $\alpha_{1}$-antitripsina) national registries. The objectives of the study were: 1 ) to analyse the differences in the clinical and demographic characteristics of patients in both countries; 2) to compare index and nonindex cases; 3) to describe the characteristics of $\mathrm{PI}^{\star} \mathrm{ZZ}$ patients with chronic obstructive pulmonary disease (COPD) according to Global Initiative for Chronic Obstructive Lung Disease (GOLD) severity classes [13]; 4) to characterise the different clinical phenotypes of $\mathrm{PI}^{\star} \mathrm{ZZ}$ patients with COPD: predominant emphysema, chronic bronchitis and overlap with asthma; and 5) to investigate the relationship between smoking consumption and impairment in lung function for $\mathrm{PI}^{\star} \mathrm{ZZ}$ and $\mathrm{PI}^{\star} \mathrm{SZ}$ subjects.

\section{Participants and registries}

We assessed AATD patients aged $\geqslant 18$ years enrolled in the REDAAT or the Italian registry of AATD from June 1993 to November 2011. REDAAT was founded in 1993 and became a part of AIR in 1999 [8, 14, 15]. This registry consists of an online questionnaire, which was first included in the website of the Sociedad Española de Neumología y Cirugı Torácica, and is now found on its own website (www.redaat.es) [14]. The criteria for inclusion are the presence of severe AATD $\left(\alpha_{1}\right.$-AT plasma concentrations $<30 \%$ of the normal value) and being the carrier of a $\mathrm{PI}^{\star} \mathrm{ZZ}$ genotype, $\mathrm{PI}^{\star} \mathrm{SZ}$ genotype or some other rare deficient phenotypic variants of the deficiency $[8,14]$. After a log-in procedure every accredited physician may access the system in order to enrol new patients or update the database. The database is registered at the Spanish Official Agency of Data Protection and has been accredited as a "certified medical website" by the College of Physicians of Barcelona (Collegi Oficial de Metges de Barcelona). Quality control of the data is regularly performed by the REDAAT coordinators.

The Italian registry of AATD was established in 1996 and became a member of AIR in 1999 [16]. Its inclusion criteria are the presence of severe $\alpha_{1}$-AT deficiency, defined by the carriage of the PI*ZZ genotype, $\mathrm{PI}^{\star} \mathrm{SZ}$ genotype or another rare severe deficient genotypic variant. The data are collected on forms sent by post or e-mail to the Italian Centre for diagnosis of AATD in Pavia, Italy, where the coordinators update the database.

\section{Laboratory diagnosis of AATD}

Laboratory diagnosis of AATD was performed in the two central laboratories in Barcelona (Spain) and Pavia (Italy), according to current diagnostic standards. These standards imply a flow chart that includes nephelometric plasma level, isoelectric focusing, rapid genotype and coding region sequencing, if needed. Both programmes use the dried blood spot method of blood collection and shipment. Technical details have been described elsewhere $[17,18]$. Although similar in the main aspects (initial decision based on $\alpha_{1}$-AT plasma level and genotyping for Z and S alleles), the algorithms used in Spain and in Italy have slight differences, which have recently been analysed [19]. All subjects entering the diagnostic procedure gave their written informed consent. 


\section{Data management and definitions}

Since both national registries are members of AIR the same database is used, thereby allowing comparisons of the data collected [9]. The data analysed included demographical and physical information, smoking habits, reason for $\alpha_{1}$-AT dosage and genotype, general and pneumological medical history, radiological features, pneumological and augmentation treatment, pulmonary function tests, liver function tests and quality-of-life assessment, as well as information related to the patient's work-life and death.

Both databases were first assessed for quality control and the frequency of missing data, then all the information included was coded in order to create a unique database. As a high-risk population, all subjects diagnosed with COPD, emphysema or chronic bronchitis by the registering physician or whose spirometry showed a post-bronchodilator forced expiratory volume in $1 \mathrm{~s}$ (FEV1) to forced vital capacity ratio of $<70 \%$ were considered to have COPD. Diagnostic delay was calculated as the difference in years between the age at diagnosis and the age at symptom onset. All subjects diagnosed through familial screening were considered to be nonindex cases.

For the classification of clinical phenotypes, we used the reported respiratory diagnosis in the database provided by the physicians in charge of the patients (mainly respiratory specialists). Emphysema was considered when no other respiratory diagnosis was mentioned $(n=267)$, with the same being performed for chronic bronchitis $(n=40)$. The diagnosis of overlap asthma-COPD was based on the reporting of asthma together with either emphysema or chronic bronchitis $(n=29)$.

The severity of COPD was based on the GOLD spirometric severity criteria [11]: I (mild) FEV1 $\geqslant 80 \%$ predicted; II (moderate) FEV1 $\geqslant 50-80 \%$ pred; III (severe) FEV1 $\geqslant 30-50 \%$ pred; and IV (very severe) FEV1 $<30 \%$ pred. For the objectives of the analysis, all patients with a clinical diagnosis of COPD, emphysema or chronic bronchitis by the attending physician were also included in the mildest category, even if spirometry did not show airflow obstruction.

\section{Statistical analyses}

Categorical variables were described by frequencies and percentages and compared using the Chi-squared test or Fisher's exact test when appropriate. Continuous variables were expressed as mean $\pm S D$ and compared between groups using the t-test or one-way ANOVA where appropriate. All post hoc comparisons were made with the Bonferroni correction for multiple comparisons. Pearson's correlation analysis was performed to determine the relationship between continuous variables. The association between FEV1 (\% pred) and pack-years in patients with the $\mathrm{PI}^{\star} \mathrm{ZZ}$ and $\mathrm{PI}^{\star} \mathrm{SZ}$ genotypes was studied by means of a logarithmic regression model. Data were processed using SPSS 17.0 (IBM SPSS, Inc., Chicago, IL, USA). The level of significance was set at 0.05 (two-tailed).

\section{Results}

Population characteristics of the Spanish and Italian patients

A total of 745 subjects was available in both databases, with 416 enrolled in the REDAAT and 329 in the Italian Registry. Of these, 426 (57.2\%) subjects were male, the mean age at enrolment was $49.9 \pm 13.8$ years and $483(64.9 \%)$ subjects were active or former smokers, with a mean tobacco consumption of $23.4 \pm 17.7$ pack-years. Dyspnoea was the principal symptom reported and the mean age at symptom onset was $39 \pm 14.8$ years. The mean age at diagnosis was $47 \pm 14.7$ years; therefore, the mean diagnostic delay was $9.0 \pm 12.1$ years. Pulmonary disease was referred in $80.4 \%$ of all subjects and $72.5 \%$ were diagnosed with COPD. Respiratory medications were taken by 456 (61.2\%) subjects, $13.2 \%$ needed oxygen therapy and 256 (34.4\%) subjects were receiving augmentation treatment (table 1 ).

In the Spanish database there was a higher predominance of males $(60.8 \%$ versus $52.6 \% ; \mathrm{p}<0.05)$, former smokers $(60.8 \%$ versus $48.9 \% ; \mathrm{p}<0.01)$ and higher tobacco consumption $(26.7$ versus 19.2 pack-years; $\mathrm{p}<0.001)$ compared with Italian patients. The reasons for the diagnosis of AATD and the diagnotic delay were similar between the groups, even if Spanish patients were younger at symptom onset (36.9 years versus 43.5 years; $\mathrm{p}<0.001)$ and at diagnosis $(45.4$ years versus 49 years; $\mathrm{p}<0.01)$. Pulmonary diseases were more prevalent in the Spanish group (table 1). Despite a similar mean FEV1\% pred, there was a higher rate of use of respiratory medications in the Spanish registry $(72.1 \%$ versus $47.4 \% ; \mathrm{p}<0.001)$. The frequency of rare alleles was higher in the Italian registry $(18.5 \%$ versus $2.9 \% ; \mathrm{p}<0.001)$. The frequency of augmentation therapy was similar in the two countries (table 1).

\section{Differential characteristics between index and nonindex cases}

Patients diagnosed due to respiratory symptoms (index cases) were more frequently male and significantly older at inclusion and at the time of diagnosis ( $48.1 \pm 14.5$ years versus $41.7 \pm 14.5$ years). In general, the 
TABLE 1 Clinical characteristics in patients with severe $\alpha_{1}$-antitrypsin deficiency (AATD), stratified by the country of origin

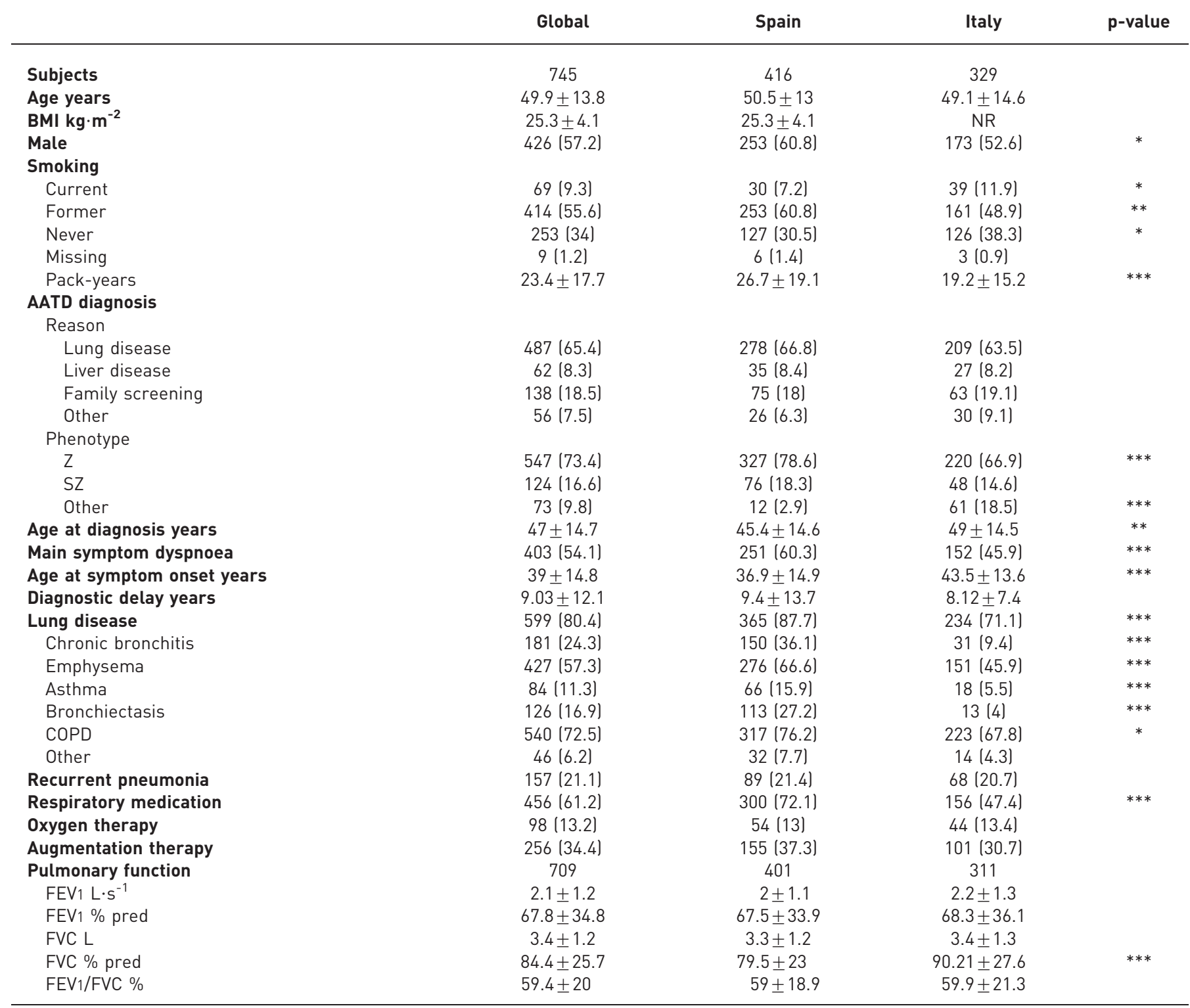

Data are presented as $\mathrm{n}$, mean $\pm \mathrm{SD}$ or $\mathrm{n}(\%)$, unless otherwise stated. BMI: body mass index; NR: not reported; COPD: chronic obstructive pulmonary disease; FEV1: forced expiratory volume in $1 \mathrm{~s} ; \%$ pred: \% predicted; FVC: forced vital capacity. ${ }^{*}: p<0.05 ;{ }^{* *}: p<0.01 ;{ }^{* * *}: p<0.001$.

prevalence of respiratory symptoms and respiratory diseases was lower in nonindex compared with index cases and their lung function parameters were significantly better preserved (table 2).

\section{Comparison among GOLD stages}

The $\mathrm{PI}^{\star} \mathrm{ZZ}$ subjects diagnosed with COPD $(\mathrm{n}=412)$ were compared according to GOLD severity stages (table 3). To avoid variability generated by the different $\alpha_{1}$-AT phenotypes, $\mathrm{PI}^{\star} \mathrm{SZ}$ individuals were excluded from this analysis and the comparison of clinical phenotypes below. The mean age was similar in groups I, III and IV, but subjects in group II were older. In GOLD stage I patients and among patients with nonobstructive spirometry, females and nonindex cases prevailed. The percentage of never-smokers significantly decreased with the increase in the severity of COPD (from 55.7\% in GOLD stage I to $11.4 \%$ in GOLD stage IV; $\mathrm{p}<0.001$ ). The groups showed a similar age at symptom onset and a similar diagnostic delay. Cases of asthma and bronchiectasis were homogenously distributed among groups. Augmentation therapy was administered to $19.4 \%$ of GOLD stage I, $48.4 \%$ of GOLD stage II, $58.9 \%$ of GOLD stage III and $50.7 \%$ of GOLD stage IV patients. 
TABLE 2 Clinical characteristics of patients with severe $\alpha_{1}$-antitrypsin deficiency (AATD), stratified by index and nonindex cases

\begin{tabular}{|c|c|c|c|}
\hline & Index & Nonindex & p-value \\
\hline Subjects & 607 & 138 & \\
\hline Age years & $50.9 \pm 13.6$ & $45.3 \pm 13.7$ & $* * *$ \\
\hline $\mathrm{BMI} \mathrm{kg} \cdot \mathrm{m}^{-2}$ & $25.3 \pm 4.2$ & $25.5 \pm 3.7$ & \\
\hline Sex & & & $* * *$ \\
\hline Male & $372(61.3)$ & $54(39.1)$ & \\
\hline Female & $235(38.7)$ & $84(60.9)$ & \\
\hline \multicolumn{4}{|l|}{ Smoking } \\
\hline Current & $49(8.2)$ & $20(14.7)$ & $*$ \\
\hline Former & $367(61.2)$ & $47(34.6)$ & $* * *$ \\
\hline Never & $184(30.7)$ & $69(50.7)$ & $* * *$ \\
\hline Pack-years & $24.6 \pm 18.3$ & $15.1 \pm 11.4$ & $* * *$ \\
\hline \multicolumn{4}{|l|}{ Country } \\
\hline Spain & $341(56.2)$ & 75 (54.3) & \\
\hline Italy & $266(43.8)$ & $63(45.7)$ & \\
\hline \multicolumn{4}{|l|}{ AATD diagnosis } \\
\hline Age at diagnosis years & $48.1 \pm 14.5$ & $41.7 \pm 14.5$ & $* * *$ \\
\hline \multicolumn{4}{|l|}{ Phenotype } \\
\hline Z & $448(73.8)$ & 99 (71.7) & \\
\hline SZ & $94(15.5)$ & $30(21.7)$ & \\
\hline Other & $64(10.6)$ & $9(6.5)$ & \\
\hline Lung disease & $514(85.1)$ & $85(62)$ & $* * *$ \\
\hline Chronic bronchitis & $162(27.5)$ & $19(14)$ & $* *$ \\
\hline Emphysema & $386(62.5)$ & $41(30.1)$ & $* * *$ \\
\hline Asthma & $62(10.5)$ & $22(16.2)$ & \\
\hline Bronchiectasis & $109(18.5)$ & $17(12.6)$ & \\
\hline COPD & 475 (78.3) & $65(47.1)$ & $* * *$ \\
\hline Other & $43(8.2)$ & $3(2.6)$ & \\
\hline \multicolumn{4}{|l|}{ Symptoms } \\
\hline Dyspnoea & $361(69)$ & $42(46.2)$ & $* * *$ \\
\hline Cough & $81(15.5)$ & $16(17.6)$ & \\
\hline Other & $11(2.1)$ & $2(2.2)$ & \\
\hline Asymptomatic & $70(13.4)$ & $31(34.1)$ & $* * *$ \\
\hline Age at symptom onset years & $39.4 \pm 14.7$ & $35.9 \pm 15.6$ & \\
\hline Diagnostic delay years & $9.5 \pm 12$ & $4.8 \pm 13$ & $* *$ \\
\hline Pneumonia & $146 \overline{(24.1)}$ & $11(8)$ & $* * *$ \\
\hline Respiratory medication & $411(74.1)$ & $45(36.6)$ & $* * *$ \\
\hline Oxygen therapy & $94(17.5)$ & 4 (3.5) & $* * *$ \\
\hline Augmentation therapy & $233(38.4)$ & $23(16.7)$ & $* * *$ \\
\hline Pulmonary function & 576 & 135 & \\
\hline FEV1 $L \cdot S^{-1}$ & $1.9 \pm 1.1$ & $2.9 \pm 1.2$ & $* * *$ \\
\hline FEV $1 \%$ pred & $61.7 \pm 32.5$ & $94.5 \pm 32$ & $* * *$ \\
\hline FVC L & $3.2 \pm 1.2$ & $3.9 \pm 1.3$ & $* * *$ \\
\hline FVC \% pred & $80.4 \pm 24.7$ & $101.1 \pm 23.3$ & $* * *$ \\
\hline FEV $1 / F V C \%$ & $56.4 \pm 19.6$ & $72 \pm 16.4$ & $* * *$ \\
\hline
\end{tabular}

Data are presented as $\mathrm{n}$, mean \pm SD or $\mathrm{n}(\%)$ unless otherwise stated. BMI: body mass index; COPD: chronic obstructive pulmonary disease; FEV1: forced expiratory volume in $1 \mathrm{~s} ; \%$ pred: \% predicted; FVC: forced vital capacity. ${ }^{*}: p<0.05{ }^{* *}: p<0.01 * * *: p<0.001$.

\section{Comparison among clinical phenotypes}

We compared the subjects with emphysema $(n=267)$, chronic bronchitis $(n=40)$ and subjects with an overlap with asthma $(n=29)$. Their general characteristics are summarised in table 4.

Patients with chronic bronchitis were younger, had more preserved lung function and lower tobacco consumption (17.3 \pm 10.8 pack-years), despite the higher number of current smokers (25\%). Overlap patients were mainly females $(55.2 \%)$, were more frequently never-smokers $(37.9 \%)$ and more often received respiratory medications $(96.6 \%)$. Augmentation treatment was taken by $47.9 \%$ of the subjects with emphysema, $27.5 \%$ of those with chronic bronchitis and $44.8 \%$ of overlap subjects. 
TABLE 3 Clinical characteristics of $\mathrm{PI}$ ZZ homozygotes stratified by Global Initiative for Chronic Obstructive Lung Disease (GOLD) status

\begin{tabular}{|c|c|c|c|c|c|}
\hline & GOLD I & GOLD II & GOLD III & GOLD IV & p-value \\
\hline Subjects & 62 & 128 & 151 & 71 & \\
\hline Age years & $50.3 \pm 15.7$ & $54.9 \pm 11$ & $51.4 \pm 10$ & $50.3 \pm 9.8$ & * \\
\hline $\mathrm{BMI}^{\#} \mathrm{~kg} \cdot \mathrm{m}^{-2}$ & $24.5 \pm 4.4$ & $25.3 \pm 3.5$ & $25.1 \pm 4.1$ & $23.6 \pm 4.1$ & \\
\hline Male & $25(\overline{40} .3)$ & $66(\overline{5} 1.6)$ & $100(66.2)$ & $58(\overline{81.7)}$ & $* * *$ \\
\hline Smoking & & & & & $* * *$ \\
\hline Current & $10(16.4)$ & $13(10.2)$ & $9(6)$ & $5(7.1)$ & \\
\hline Former & 17 (27.9) & $76(59.4)$ & $121(80.1)$ & 57 (81.4) & \\
\hline Never & 34 (55.7) & 39 (30.5) & $21(13.9)$ & $8(11.4)$ & \\
\hline Pack-years & $12.6 \pm 14.2$ & $21 \pm 14.4$ & $24.3 \pm 13.5$ & $26.4 \pm 16.7$ & $* *$ \\
\hline \multicolumn{6}{|l|}{ Reason for AATD diagnosis } \\
\hline Lung disease & $27(44.3)$ & 103 (80.5) & $136(90.1)$ & 67 (94.4) & \\
\hline Liver disease & $7(11.5)$ & $1(3.1)$ & $4(2.6)$ & $0(0)$ & \\
\hline Family screening & $23(37.7)$ & 17 (13.3) & $11(7.3)$ & $4(5.6)$ & \\
\hline Other & $4(6.6)$ & $4(3.1)$ & $0(0)$ & $0(0)$ & \\
\hline Age at diagnosis years & $44.8 \pm 17.8$ & $51.7 \pm 12.3$ & $48.8 \pm 10.1$ & $47.7 \pm 9.7$ & $* *$ \\
\hline Main symptom dyspnoea \% & 46.41 & 74.8 & 79.9 & 77.1 & \\
\hline Age at symptom onset years & $37.8 \pm 18.4$ & $40.9 \pm 12.6$ & $39.9 \pm 12.1$ & $37.5 \pm 11.1$ & \\
\hline Diagnostic delay years & $9.9 \pm 17.8$ & $9.5 \pm 13.7$ & $8.1 \pm 9.4$ & $9.5 \pm 9.3$ & \\
\hline \multicolumn{6}{|l|}{ Lung disease } \\
\hline Chronic bronchitis & 15 (24.2) & 49 (38.3) & $56(37.1)$ & 16 (22.5) & * \\
\hline Asthma & $10(16.1)$ & $15(11.7)$ & $15(10)$ & $3(4.2)$ & \\
\hline Emphysema & $41(66.1)$ & $101(78.9)$ & $127(84.1)$ & 61 (85.9) & * \\
\hline Bronchiectasis & 14 (23.3) & $33(25.8)$ & $34(22.5)$ & $10(14.1)$ & \\
\hline Others & $6(12.8)$ & $3(3)$ & $16(12.2)$ & $4(6.3)$ & \\
\hline Pneumonia & $12(19.4)$ & $38(29.7)$ & $38(25.2)$ & $19(26.8)$ & \\
\hline Respiratory medication & $32(52.5)$ & $107(88.4)$ & $131(92.9)$ & 64 (98.5) & $* * *$ \\
\hline Oxygen therapy & $3(5.4)$ & $12(10.3)$ & $30(21.3)$ & $24(37.5)$ & $* * *$ \\
\hline Augmentation therapy & $12(19.4)$ & $62(48.4)$ & 89 (58.9) & $36(50.7)$ & $* * *$ \\
\hline Pulmonary function & & & & & $* * *$ \\
\hline $\mathrm{FEV} 1 \mathrm{~L} \cdot \mathrm{S}^{-1}$ & $2.8 \pm 0.8$ & $1.8 \pm 0.5$ & $1.2 \pm 0.3$ & $0.8 \pm 0.2$ & $* * *$ \\
\hline FEV $1 \%$ pred & $98.7 \pm 16.3$ & $62.7 \pm 8.3$ & $36.9 \pm 5.7$ & $23.4 \pm 4$ & $* * *$ \\
\hline FVC L & $3.9 \pm 1$ & $3.3 \pm 1.2$ & $3 \pm 1$ & $2.3 \pm 0.9$ & $* * *$ \\
\hline FVC \% pred & $104.8 \pm 15.7$ & $86.6 \pm 18.2$ & $71.7 \pm 18.2$ & $50.7 \pm 15.6$ & $* * *$ \\
\hline $\mathrm{FEV}_{1} / \mathrm{FVC} \%$ & $71.1 \pm 11.1$ & $55.2 \pm 110.8$ & $43.6 \pm 10.6$ & $36.9 \pm 9$ & $* * *$ \\
\hline
\end{tabular}

Values are given as $n$, mean \pm SD or $n(\%)$, unless otherwise stated. BMI: body mass index; AATD: $\alpha_{1}$-antitrypsin deficiency; FEV1: forced expiratory volume in $1 \mathrm{~s} ; \%$ pred: $\%$ predicted; FVC: forced vital capacity. ${ }^{\#}$ : not available for patients from the Italian registry. ${ }^{*}: \mathrm{p}<0.05 ;{ }^{* *}: \mathrm{p}<0.01$; $* * *: p<0.001$.

\section{Comparison between $\alpha_{1}$-AT genotypes}

A total of $547(73.4 \%)$ subjects carried the $\mathrm{PI}^{\star} \mathrm{ZZ}$ genotype and $124(16.6 \%)$ the $\mathrm{PI}^{\star} \mathrm{SZ}$. The groups were similar in age, body mass index and sex distribution. The PI*SZ subjects were older at the time of diagnosis, less symptomatic and had a lower prevalence of lung disease compared to those with $\mathrm{PI}^{\star} \mathrm{ZZ}$. They also had more preserved lung function (mean FEV1 89.9\% versus $63.2 \%$ for $\mathrm{PI}^{\star} \mathrm{ZZ} ; \mathrm{p}<0.001$ ). Respiratory medications were more frequent among $\mathrm{PI}^{\star} \mathrm{ZZ}$ subjects $(66.2 \%$ versus $41.9 \% ; \mathrm{p}<0.001)$ and the rate of augmentation therapy was higher in this group (39.7\% versus $8.1 \%$ ) (table 5 ).

We observed a significant association between FEV1 \% pred and pack-years in patients with the $\mathrm{PI}^{\star} \mathrm{ZZ}^{\mathrm{Z}}$ genotype $\left(R^{2}=0.26 ; p<0.001\right)$ as well as in patients with the $\mathrm{PI}^{\star} S Z$ genotype $\left(\mathrm{R}^{2}=0.32 ; \mathrm{p}<0.001\right)$ (fig. 1$)$.

\section{Discussion}

Research on rare diseases is hampered by the difficulties in collecting enough individuals for clinical and epidemiological studies. The World Health Organization has acknowledged the need for large populationbased registries of AATD in order to foster basic and clinical investigations as well as to conduct clinical trials of new treatments [10]. Registries provide a unique opportunity to compare large enough populations from different countries to explore the characteristics of patients and the patterns of medical care. In this study, we compared the characteristics of Spanish and Italian patients included in their national registries. 
TABLE 4 Clinical characteristics of $\mathrm{PI}$ *ZZ homozygotes, stratified by obstructive lung disease phenotype

\begin{tabular}{|c|c|c|c|c|}
\hline & Emphysema & Chronic bronchitis & Asthma overlap & p-value \\
\hline Subjects & 267 & 40 & 29 & \\
\hline Age years & $53 \pm 11.3$ & $47.7 \pm 14.3$ & $51.9 \pm 12.8$ & $*$ \\
\hline $\mathrm{BMI}^{\#} \mathrm{~kg} \cdot \mathrm{m}^{-2}$ & $24.6 \pm 3.6$ & $24.5 \pm 4.1$ & $27.1 \pm 5.4$ & $*$ \\
\hline Male & $174(65.2)$ & $19(\overline{47.5)}$ & $13(\overline{44.8)}$ & $*$ \\
\hline Smoking & & & & $* * *$ \\
\hline Current & $19(7.1)$ & $10(25)$ & $1(3.4)$ & \\
\hline Former & $192(72.2)$ & $16(40)$ & $17(58.6)$ & \\
\hline Never & $55(20.7)$ & $14(35)$ & 11 (37.9) & \\
\hline Pack-years & $23.7 \pm 15.6$ & $17.3 \pm 10.8$ & $24.9 \pm 18.3$ & \\
\hline \multicolumn{5}{|l|}{ Reason for AATD diagnosis } \\
\hline Lung disease & 277 (85) & $29(74.4)$ & $25(86.2)$ & \\
\hline Liver disease & $7(2.6)$ & $1(2.6)$ & $2(6.9)$ & \\
\hline Family screening & $26(9.7)$ & $3(7.7)$ & $2(6.9)$ & \\
\hline Other & $7(2.6)$ & $3(7.7)$ & $0(0)$ & \\
\hline Genotype & & & & $*$ \\
\hline Z & $210(78.9)$ & $25(62.5)$ & $22(75.9)$ & \\
\hline $\mathrm{SZ}$ & $20(7.5)$ & $6(15)$ & $6(20.7)$ & \\
\hline Other & 36 (13.5) & 9 (22.5) & $1(3.4)$ & \\
\hline Age at diagnosis years & $50.4 \pm 12.3$ & $46.3 \pm 14.2$ & $49.8 \pm 15.8$ & \\
\hline Main symptoms dyspnoea & $204 \overline{(80.6)}$ & $16(\overline{4} 5.7)$ & $25(\overline{8} 9.3)$ & \\
\hline Age at symptom onset years & $40.6 \pm 13.5$ & $39.1 \pm 14.8$ & $37.6 \pm 13.3$ & \\
\hline Diagnostic delay years & $9.5 \pm 13.4$ & $6.2 \pm 6.1$ & $10 \pm 12.9$ & \\
\hline Bronchiectasis & $40(15.1)$ & $9(22.5)$ & $5(17.9)$ & \\
\hline Pneumonia & $69(25.8)$ & $11(27.4)$ & $4(13.8)$ & \\
\hline Respiratory medication & $210(84.7)$ & $17(50)$ & $28(96.6)$ & $* * *$ \\
\hline Oxygen therapy & $58(23.4)$ & $0(0)$ & $6(20.7)$ & $* *$ \\
\hline Augmentation treatment & $128(47.9)$ & $11(27.5)$ & 13 (44.8) & \\
\hline \multicolumn{5}{|l|}{ Pulmonary function } \\
\hline $\mathrm{FEV} 1 \mathrm{~L} \cdot \mathrm{S}^{-1}$ & $1.5 \pm 0.8$ & $2.3 \pm 1.1$ & $1.5 \pm 0.7$ & $* * *$ \\
\hline FEV1 \% pred & $49.6 \pm 25.6$ & $72.9 \pm 31.8$ & $55.4 \pm 23.8$ & $* * *$ \\
\hline FVC L & $3.1 \pm 1.2$ & $3.4 \pm 1.1$ & $2.9 \pm 1.2$ & \\
\hline FVC \% pred & $76.8 \pm 24.7$ & $87.9 \pm 21.1$ & $75.9 \pm 26.1$ & $*$ \\
\hline FEV1/FVC \% & $47.9 \pm 14.9$ & $66.1 \pm 18.1$ & $55 \pm 17.8$ & $* * *$ \\
\hline
\end{tabular}

Data are presented as $\mathrm{n}$, mean \pm SD or $\mathrm{n}(\%)$, unless otherwise stated. BMI: body mass index; AATD: $\alpha_{1}$-antitrypsin deficiency; FEV1: forced expiratory volume in $1 \mathrm{~s}$; \% pred: \% predicted; FVC: forced vital capacity. ${ }^{\#}$ : not available for patients from the Italian registry. ${ }^{*}$ : p<0.05; ${ }^{* *}: \mathrm{p}<0.01 ;{ }^{* * *}: \mathrm{p}<0.001$.

Since both registries are included in the AIR [11], they share the same database, thereby allowing direct comparisons of data and pooling of data for further analysis.

The characteristics of the patients were somewhat different to those described 15 years ago for the large National Heart, Lung and Blood Institute (NHLBI) Registry in the USA [20]. The mean age in the USA registry was 46 years, $55.5 \%$ were males and the mean FEV1 was $46.7 \%$ pred, compared with 49.7 years, $56.9 \%$ males and a mean FEV1 of $63.2 \%$ pred in our series. This difference in mean FEV1 \% pred indicates the larger number of nonindex cases in our study, which may be a positive consequence of the family screening programmes developed in both Spain and Italy $[16,18]$.

Spanish patients were significantly younger at the onset of symptoms and diagnosis; however, the diagnostic delay did not significantly differ between the two countries. Diagnostic delay continues to be an important hurdle to achieve appropriate care of patients with AATD. In the USA there was an improvement in the length of diagnostic delay from 7.2 years in 1994 to 5.6 years in 2003 [21], similar to the 6-year delay observed in Germany and Austria [22]. Unfortunately, the situation in Spain and Italy is worse with a mean delay of 9 years. More awareness campaigns are needed, especially among primary care physicians who care for most patients with COPD, particularly in early stages of the disease [23]. Another interesting difference is the higher prevalence of rare genotypes in Italy compared with Spain, which is in accordance with previous reports $[24,25]$ and could be related to the differences between the two nationwide diagnostic algorithms [19]. A list of the rare genotypes reported in the two registries is available as online supplementary material. 


\begin{tabular}{|c|c|c|c|}
\hline & $\mathbf{Z Z}$ & SZ & $p$-value \\
\hline Subjects & 547 & 124 & \\
\hline Male & $311(56.9)$ & $67 \overline{(54)}$ & \\
\hline \multicolumn{4}{|l|}{ Smoking } \\
\hline Current & 49 (9) & $13(10.5)$ & \\
\hline Missing & $8(1.5)$ & $1(0.8)$ & \\
\hline Pack-years & $21.6 \pm 15$ & $34 \pm 27.5$ & $* * *$ \\
\hline \multicolumn{4}{|l|}{ Reason for AATD diagnosis } \\
\hline Lung disease & $381(69.7)$ & $57(46)$ & $* * *$ \\
\hline Liver disease & $36(6.6)$ & $22(17.7)$ & $* * *$ \\
\hline Family screening & $99(18.1)$ & $30(24.2)$ & \\
\hline Diagnostic delay years & $9.1 \pm 12.1$ & $9.5 \pm 13.3$ & \\
\hline Lung disease & $466(85.2)$ & $76(61.3)$ & $* * *$ \\
\hline Chronic bronchitis & $142(26)$ & $28(22.6)$ & \\
\hline Emphysema & $345(63.1)$ & $42(33.9)$ & $* * *$ \\
\hline Asthma & $60(11)$ & $22(17.7)$ & \\
\hline Bronchiectasis & $104(19)$ & $16(12.9)$ & \\
\hline COPD & $429(78.4)$ & $54(43.5)$ & $* * *$ \\
\hline Other & $32(5.8)$ & $10(8.1)$ & \\
\hline Recurrent pneumonia & $122(22.3)$ & $19(15.3)$ & \\
\hline Respiratory medication & $362(66.2)$ & 52 (41.9) & $* * *$ \\
\hline Oxygen therapy & $71(13)$ & $14(11.3)$ & \\
\hline Augmentation treatment & $217(39.7)$ & $10(8.1)$ & $* * *$ \\
\hline
\end{tabular}

Data are presented as $n$, mean \pm SD or $n(\%)$, unless otherwise stated. BMI: body mass index; AATD: $\alpha_{1}$-antitrypsin deficiency; FEV1: forced expiratory volume in $1 \mathrm{~s}$; $\%$ pred: $\%$ predicted; FVC: forced vital capacity. ${ }^{\#}$ : not available for patients from the Italian registry. ${ }^{*}$ : $p<0.05$; ${ }^{* *}: \mathrm{p}<0.01 ;{ }^{* * *}: \mathrm{p}<0.001$.

When patients with criteria for COPD were analysed, we observed that the mean age was very similar across all the GOLD severity stages from I to IV. In contrast, as the severity of COPD increased, the proportion of males and ever smokers also rose. The prevalence of other respiratory conditions, such as bronchiectasis or episodes of pneumonia, was not related to the severity of COPD. Up to $19.4 \%$ of the patients in the GOLD I severity group were receiving augmentation therapy, although guidelines do not recommend the initiation of therapy in individuals with preserved lung function $[2,26,27]$. Similarly, in the NHLBI registry $11 \%$ of patients with FEV1 $>80 \%$ pred were receiving augmentation therapy [20]. It is important to consider that nonindex cases without augmentation therapy may have the same survival as the general population if they do not smoke [28].

According to the predominance of symptoms, AATD is a very heterogeneous disease [29], and patients may be classified into different clinical phenotypes [30, 31]. Most of the patients were classified by their physicians as having pulmonary emphysema, whereas a smaller number presented a predominance of other phenotypes. 9\% had also been diagnosed with asthma, which has been described as an overlap COPDasthma phenotype [32]. This $9 \%$ is somewhat lower than the $13 \%$ of overlap phenotype described in the COPDGene cohort composed of COPD smokers [32]. Compared to other series of patients with AATD, the percentage found in our study is much lower than the $31 \%$ of prevalence of asthma in the NHLBI registry [20] and the 38.6\% reported in the Alpha One Foundation Research Network Registry [9]. Our patients 


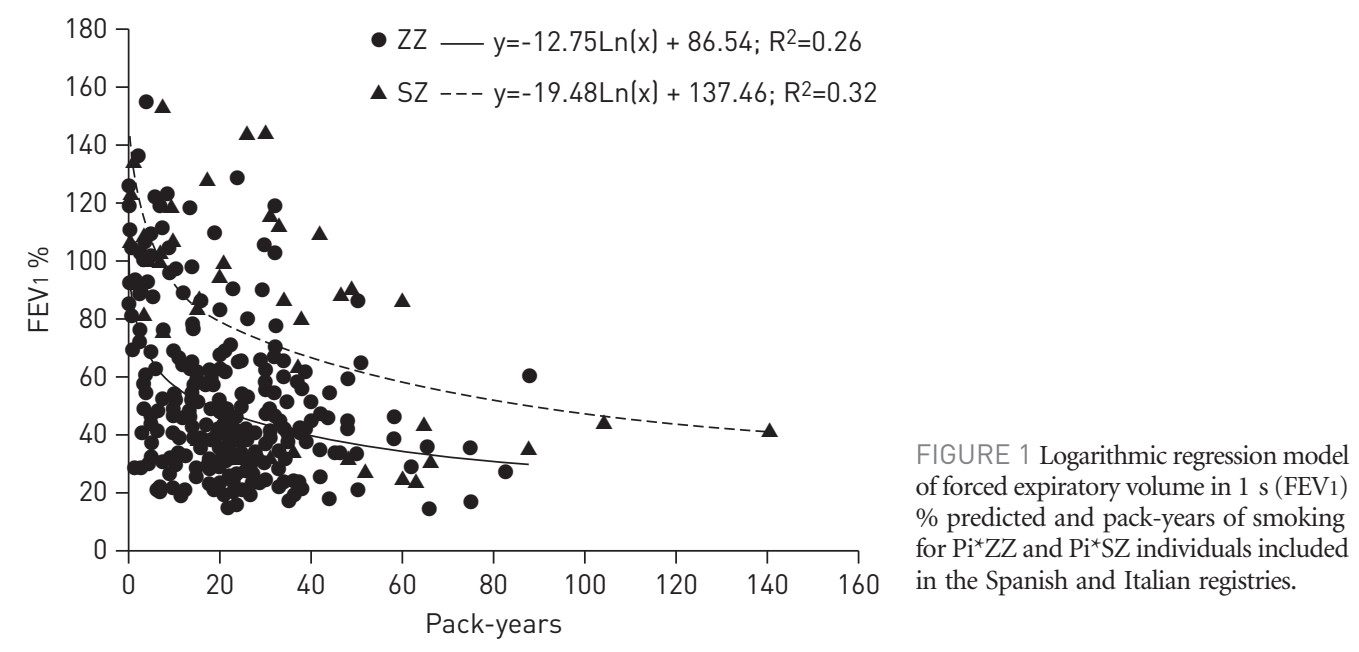

with overlap COPD-asthma were more frequently female, never-smokers; the mean age at diagnosis was 37.6 years and $45 \%$ were under augmentation therapy.

The prevalence of bronchiectasis in our series was $16.9 \%$, being higher in Spain (27.2\%) than in Italy (4\%). It is not possible to ascertain whether this difference is real or due to the different frequency of assessment of patients using computed tomography (CT). Interestingly, in a well-characterised series of patients with AATD studied using CT scans, PARR et al. [33] found exactly the same $27 \%$ prevalence of clinically significant bronchiectasis as that in the Spanish cohort. Patients with bronchiectasis had a greater impairment in physiology and health status [33], underlining the importance of the identification of bronchiectasis in this population. The identification of clinical phenotypes may have an impact in the selection of respiratory medications [34].

There is controversy about the susceptibility of the protease inhibitor SZ genotype ( $\mathrm{PI}^{\star} \mathrm{SZ}$ ) to develop pulmonary emphysema. A meta-analysis of case-control and cohort studies suggested that patients with $\mathrm{PI}^{\star S Z}$ have an odds ratio of 3.26 (95\% CI 1.24-8.57) for the development of COPD [35]. However, if one unusually positive study is discounted [36], no increased risk was observed. In an attempt to investigate their natural history, the AIR also included $\mathrm{Pi}^{\star} \mathrm{SZ}$ individuals [11]. We observed that $\mathrm{PI}^{\star} \mathrm{SZ}$ subjects had more preserved lung function, despite a higher mean smoking consumption, which is in agreement with previous studies describing less emphysema on CT scans and less abnormal respiratory physiology test results in $\mathrm{PI}^{\star} \mathrm{SZ}$ compared with matched subjects with $\mathrm{PI}^{\star} \mathrm{ZZ}$ [37]. On plotting the smoking consumption with the FEV1 \% pred in both groups of individuals with $\mathrm{PI}^{\star} \mathrm{SZ}$ and $\mathrm{PI}^{\star} \mathrm{ZZ}$, we observed the same type of curve, demonstrating a significant relationship between a higher smoking consumption and a lower FEV $1 \%$ pred for the two genotypes. However, the curve of $\mathrm{PI}^{\star} \mathrm{SZ}$ individuals was displaced by $20-30 \%$, meaning that for any given quantity of smoking consumption a $\mathrm{PI}^{\star} \mathrm{SZ}$ subject had an FEV $1 \%$ pred that was between $20 \%$ and $30 \%$ better than a $\mathrm{Pi}^{\star} \mathrm{ZZ}$ subject. If we bear in mind the marked difference in confidence intervals of $\alpha_{1}$-AT serum level values in $\mathrm{PI}^{\star} \mathrm{ZZ}$ and $\mathrm{PI}^{\star} \mathrm{SZ}$ individuals [38], this would further support the concept that the risk for lung impairment is inversely related to serum $\alpha_{1}$-AT levels. Another interesting observation from the curve was that the impact of smoking is greater at the beginning of the habit. There was steeper decline in lung function with the first 20 pack-years of smoking compared with consequent consumption for both genotypes. It is possible that a survivor effect accounted for the mild decline in FEV1\% pred at the end of the curve, but it is difficult to accept a significant survivor effect influencing the results obtained at the beginning of the curve at low levels of smoking, when the curve is steeper. These results highlight the importance of early identification of subjects with AATD, particularly at an age when they have not started smoking. Family screening is one of the best strategies to detect early cases and prevent the evolution of the disease by vigorous counselling against smoking.

The indication of augmentation therapy in $\mathrm{PI}^{\star} \mathrm{SZ}$ is not clear $[2,26]$; however, $8 \%$ of our $\mathrm{PI}^{\star} \mathrm{SZ}$ subjects were on augmentation (mean FEV1 $58.8 \%$ pred). It is not possible to ascertain which criteria were used for starting therapy in this particular subgroup. Augmentation therapy is a limited and expensive resource and must be prescribed under strict criteria based on the best evidence available. The observation of augmentation therapy in patients with the $\mathrm{PI}^{\star} \mathrm{SZ}$ genotype and in patients with normal lung function requires further investigation. 
Data derived from large AATD registries have provided information about different aspects of the disease, including its natural course $[20,39]$. However, no information on the characteristics of COPD and its different clinical phenotypes in AATD individuals has been available. The current data provide new information that helps to better characterise patients with this rare disease [40].

\section{Acknowledgements}

The authors wish to thank Albert Gabarrús (Hospital Clinic, Barcelona, Spain) for his support in the statistical analysis. We also want to acknowledge the work of the members of the registries that provided information about their patients. The Italian AATD detection programme gratefully acknowledges the continuing support from Talecris/Grifols, Kedrion Italy and the Fondazione IRCCS Policlinico San Matteo. The Spanish registry also acknowledges the continuing support from Talecris/Grifols.

\section{References}

Stoller JK, Aboussouan LS. A review of $\alpha_{1}$-antitrypsin deficiency. Am J Respir Crit Care Med 2012; 185: 246-259. American Thoracic Society, European Respiratory Society. American Thoracic Society/European Respiratory Society statement: standards for the diagnosis and management of individuals with alpha- 1 antitrypsin deficiency. Am J Respir Crit Care Med 2003; 168: 818-900.

3 Blanco I, De Serres FJ, Fernández-Bustillo E, et al. Estimated numbers and prevalence of PI*S and $\mathrm{PI}^{\star} \mathrm{Z}$ alleles of $\alpha_{1}$ antitrypsin deficiency European countries. Eur Respir J 2006; 27: 77-84.

4 Luisetti M, Seersholm N. Alpha1-antitrypsin deficiency 1: epidemiology of alpha1-antitrypsin deficiency. Thorax 2004; 59: 164-169.

5 Leiden Open Variation Database. Serpina 1 homepage. https://research.cchmc.org/LOVD2/home.php?select_db= SERPINA1 Date last accessed: September 10, 2012. Date last updated: May 6, 2010.

6 National Center for Biotechnology Information (NCBI). dbSNP Short Genetic Variations. www.ncbi.nlm.nih.gov/ SNP/snp_ref.cgi?locusId=5265 Date last accessed: September 10, 2012.

7 Laurell CB, Eriksson A. The electrophoretic $\alpha-1$ globulin pattern of serum in $\alpha-1$ antitrypsin deficiency. Scand J Clin Lab Invest 1963; 15: 132-140.

8 Miravitlles M, Vidal R, Barros-Tizón JC, et al. Usefulness of a national registry of alpha-1-antitrypsin deficiency. The Spanish experience. Respir Med 1998; 92: 1181-1187.

9 Stoller JK, Brantly M, Fleming LE, et al. Formation and current results of a patient-organized registry for alpha(1)antitrypsin deficiency. Chest 2000; 118: 843-848.

10 Alphal-antitrypsin deficiency: memorandum from a WHO meeting. Bull World Health Organ 1997; 75: 397-415.

11 Stockley RA, Luisetti M, Miravitlles M, et al. Ongoing research in Europe: Alpha One International Registry (AIR) objectives and development. Eur Respir J 2007; 29: 582-586.

12 Rachelefsky G, Hogarth DK. Issues in the diagnosis of alpha 1-antitrypsin deficiency. J Allergy Clin Immunol 2008; 121: 833-838.

13 Global Initiative for Chronic Obstructive Lung Disease (GOLD). Global strategy for the diagnosis, management, and prevention of chronic obstructive pulmonary disease. www.goldcopd.org/guidelines-global-strategy-fordiagnosis-management.html Date last accessed: July 10, 2012. Date last updated: February 2013.

14 Lara B, de la Roza C, Vilà S, et al. Development and results of the Spanish registry of patients with alpha-1antitrypsin deficiency. Int J Chron Obstruct Pulmon Dis 2007; 2: 393-398.

15 Lara B, Morales P, Blanco I, et al. Registros de enfermedades respiratorias en España: fundamentos y organización. [Respiratory disease registries in Spain: fundamentals and organization.]. Arch Bronconeumol 2011; 47: 389-396.

16 Luisetti M, Massi G, Massobrio M, et al. A national program for detection of alpha 1-antitrypsin deficiency in Italy. Gruppo I.D.A. Respir Med 1999; 93: 169-172.

17 Ferrarotti I, Scabini R, Campo I, et al. Laboratory diagnosis of alpha1-antitrypsin deficiency. Transl Res 2007; 150: 267-274.

18 De la Roza C, Rodríguez-Frías F, Lara B, et al. Results of a case-detection programme for alpha-1-antitrypsin deficiency in COPD patients. Eur Respir J 2005; 26: 616-622.

19 Miravitlles M, Herr C, Ferrarotti I, et al. Laboratory testing of individuals with severe alpha 1-antitrypsin deficiency in three European Centres. Eur Respir J 2010; 35: 960-968.

20 McElvaney NG, Stoller JK, Buist AS, et al. Baseline characteristics of enrollees in the National Heart, Lung and Blood Institute Registry of alpha 1-antitrypsin deficiency. Alpha 1-Antitrypsin Deficiency Registry Study Group. Chest 1997; 111: 394-403.

21 Stoller JK, Sandhaus RA, Turino G, et al. Delay in diagnosis of alpha-1 antitrypsin deficiency. A continuing problem. Chest 2005; 128: 1989-1994.

22 Köhlein T, Janciauskiene S, Welte T. Diagnostic delay and clinical modifiers in alpha-1 antitrypsin deficiency. Ther Adv Respir Dis 2010; 4: 279-287.

23 Molina J, Flor X, García R, et al. The IDDEA project: a strategy for the detection of alpha-1 antitrypsin deficiency in COPD patients in the primary care setting. Ther Adv Respir Dis 2011; 5: 237-243.

24 Rodriguez-Frias F, Miravitlles M, Vidal R, et al. Rare alpha-1-antitrypsin variants: are they really so rare? Ther $A d v$ Respir Dis 2012; 6: 79-85.

25 Ferrarotti I, Baccheschi J, Zorzetto M, et al. Prevalence and phenotype of subjects carrying rare variants in the Italian registry for alphal-antitrypsin deficiency. J Med Genet 2005; 42: 282-287.

26 Tonelli AR, Brantly ML. Augmentation therapy in alpha-1 antitrypsin deficiency: advances and controversies. Ther Adv Respir Dis 2010; 4: 289-312.

27 Vidal R, Blanco I, Casas F, et al. Diagnóstico y tratamiento del deficit de alfa-1-antitripsina. [Guidelines for the diagnosis and management of alpha-1 antitrypsin deficiency.]. Arch Bronconeumol 2006; 42: 645-659.

28 Seersholm N, Kok-Jensen A, Dirksen A. Survival of patients with severe alpha-1 antitrypsin deficiency with special reference to non-index cases. Thorax 1994; 49: 695-698.

29 Silverman EK, Pierce JA, Province MA, et al. Variability of pulmonary function in alpha-1 antitrypsin deficiency: clinical correlates. Ann Intern Med 1989; 111: 982-991. 
30 Han MK, Agustí A, Calverley PM, et al. Chronic obstructive pulmonary disease phenotypes: the future of COPD. Am J Respir Crit Care Med 2010; 182: 598-604.

31 Miravitlles M, Calle M, Soler-Cataluña JJ. Fenotipos clínicos de la EPOC. Identificación, definición e implicaciones para las guías de tratamiento. [Clinical phenotypes of COPD: identification, definition and implications for guidelines.]. Arch Bronconeumol 2012; 48: 86-98.

32 Hardin M, Silverman EK, Barr RG, et al. The clinical features of the overlap between COPD and asthma. Respir Res 2011; 12: 127.

33 Parr DG, Guest PG, Reynolds JH, et al. Prevalence and impact of bronchiectasis in alpha-1 antitrypsin deficiency. Am J Respir Crit Care Med 2007; 176: 1215-1221.

34 Miravitlles M, Soler-Cataluña JJ, Calle M, et al. Guía Española de la EPOC (GesEpoc). Tratamiento farmacológico de la EPOC estable. [Spanish COPD guidelines (GesEPOC). Pharmacological treatment of stable COPD. Spanish Society of Pulmonology and Thoracic Surgery.]. Arch Bronconeumol 2012; 48: 247-257.

35 Dahl M, Hersh CP, Ly NP, et al. The protease inhibitor PI ${ }^{\star}$ S allele and COPD: a meta-analysis. Eur Respir J 2005; 26: 67-76.

36 Bartmann K, Fooke-Achterrath M, Koch G, et al. Heterozygosy in the Pi-system as a pathogenetic cofactor in chronic obstructive pulmonary disease (COPD). Eur J Respir Dis 1985; 66: 284-296.

37 Holme J, Stockley RA. CT scan appearance, densitometry, and health status in protease inhibitor SZ alpha-1 antitrypsin deficiency. Chest 2009; 136: 1284-1290.

38 Ferrarotti I, Thun GA, Zorzetto M, et al. Serum levels and genotype distribution of $\alpha 1$-antitrypsin in the general population. Thorax 2012; 67: 669-674.

39 Tirado-Conde G, Lara B, Casas F, et al. Factores asociados a la evolución de la function pulmonary en pacientes con deficit de alfa-1-antitripsina del registro español. [Factors associated with the evolution of lung function in patients with alpha-1 antitrypsin deficiency in the Spanish registry.]. Arch Bronconeumol 2011; 47: 495-503.

40 Luisetti M, Balfour-Lynn IM, Johnson SR, et al. Perspectives for improving the evaluation and access of therapies for rare lung diseases in Europe. Respir Med 2012; 106: 759-768. 